\title{
Time to dot the I's and cross the T's of high-sensitivity cardiac troponin
}

\author{
Cesario F. Bianchi, MD, PhD
}

\footnotetext{
From the Universidade de Mogi das Cruzes and Clinica Integracta, Núcleos de Pesquisa Tecnológica/Biotecnológica, Faculdade de Medicina, Mogi das Cruzes, São Paulo, Brazil.

Disclosures: Author has nothing to disclose with regard to commercial support.

Received for publication May 12, 2017; accepted for publication May 23, 2017; available ahead of print June 27, 2017.

Address for reprints: Cesario F. Bianchi, MD, PhD, Universidade de Mogi das Cruzes, Av. Dr. Cândido Xavier de Almeida e Souza, 200 Cep: 08780-911, Mogi das Cruzes, São Paulo, Brazil (E-mail: cesariobianchi@ gmail.com). J Thorac Cardiovasc Surg 2017;154:904-5 $0022-5223 / \$ 36.00$

Copyright (c) 2017 by The American Association for Thoracic Surgery http://dx.doi.org/10.1016/j.jtcvs.2017.05.067
}

Myocardial damage including acute myocardial infarction (AMI) during the perioperative period is a major concern for surgeons because it has a strong association with the worst short- and long-term patient outcomes. ${ }^{1,2}$

Biomarkers for AMI are now highly sensitive and specific. The high-sensitivity (hs) cardiac troponin (cTn) assay (for both cTn I and cTnT subunits) is the most advanced test for AMI. ${ }^{3}$ The hscTnT test was approved by the Food and Drug Administration in January of 2017. However, the hscTn assays come with a price because the hscTn test also detects cTn in plasma of healthy people, as well as a broader spectrum of other morbidities.

How should the hscTn assay be used with acceptable positive predictive value (PPV) and efficacy to rule in or rule out AMI? The assay-specific $99^{\text {th }}$ percentile value reference $\left(99^{\text {th }}\right)$ of cTn levels at a single time point in healthy people helps define who has an AMI. The reference change value (RCV) depends on the methods and whether it is increasing or decreasing allows the separation between chronic and acute events or diseases. Above a certain $99^{\text {th }}$ cutoff level or RCV, cTn levels a few hours apart can satisfactorily rule in or rule out AMI in patients in the emergency department. $^{5-7}$

Refinements of the 12-lead electrocardiography (ECG) and transthoracic echocardiography (TTE) with more precise recordings and better imaging quality increased the PPV but decreased efficacy. Learning how ECG and TTE combined with hscTn can yield more precise and faster AMI detection will come with prospective rigorous scientific studies and clinical experience for a stronger "evidencebased medicine."

It is important to note that if the first screening is performed with a less-sensitive method such as ECG and TTE, the degree of RCV will be greater compared with a more sensitive assay because smaller infarctions will be detectable (eg, hsTnT) ${ }^{8}$ that may have been missed by ECG or TTE.

In this issue of the Journal, Cubero-Gallego and colleagues $^{9}$ delineate cutoffs for hscTnT and creatine the $99^{\text {th }} .10$

\section{References} 2373-9.e2371.

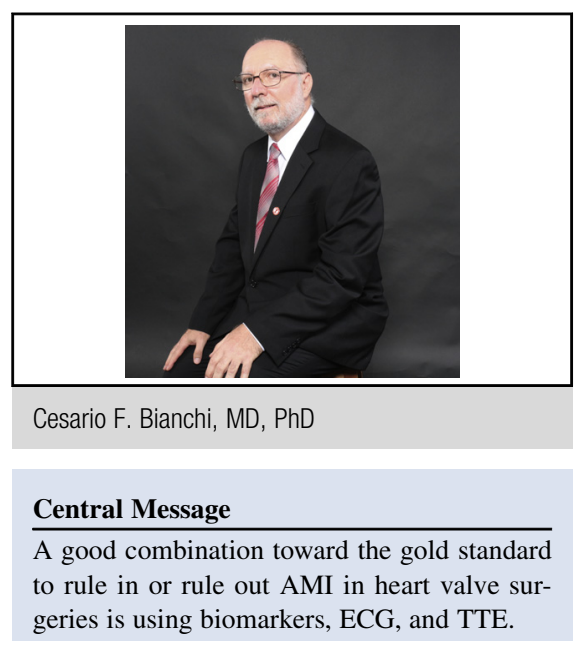

See Article page 895

kinase-MB (CK-MB) for the ECG or TTE diagnostic of AMI in patients undergoing heart valve surgery on the basis of their surgical service data. They also prospectively show that the screening proposed predicts to a great extent the long-term (30 days and 2 years) outcomes. On the other hand, smaller infarctions may be missed by ECG and TTE, and relatively high levels of cTn will be considered normal. Thus, the cutoff defined by Cubero-Gallego and colleagues $^{9}$ arbitrarily estimated to be greater than 10 times

However, this worthwhile study missed an important data point: to take advantage of the hscTn assay and an RCV between the levels preoperatively (not available) and admission to the intensive care unit (ICU) within 3 hours. This RCV could be ideal for studies using hscTn assays. Diagnostics could have been made earlier and appropriate treatment instituted. Indeed, the normal-sensitivity cTn assays may have performed similarly (16-24 hours after admission to the ICU) to the regular-sensitivity CK-MB.

More studies using hscTn assays are needed to refine an early and precise algorithm to rule in or rule out perioperative heart valve surgery associated with AMI.

1. Lurati Buse GA, Koller MT, Grapow M, Bolliger D, Seeberger M, Filipovic M. The prognostic value of troponin release after adult cardiac surgery - a meta-analysis. Eur J Cardiothorac Surg. 2010;37:399-406.

2. Paparella D, Guida P, Caparrotti S, Fanelli V, Martinelli G, Mazzei V, et al. Myocardial damage influences short- and mid-term survival after valve surgery: a prospective multicenter study. J Thorac Cardiovasc Surg. 2014;148: 
3. Garg P, Morris P, Fazlanie AL, Vijayan S, Dancso B, Dastidar AG, et al. Cardiac biomarkers of acute coronary syndrome: from history to high-sensitivity cardiac troponin. Intern Emerg Med. 2017;12:147-55.

4. Jaffe AS, Ordonez-Llanos J. High-sensitivity cardiac troponin: from theory to clinical practice. Rev Esp Cardiol (Engl Ed). 2013;66:687-91.

5. Writing Committee for the VISION Study Investigators, Devereaux PJ, Biccard BM, Sigamani A, Xavier D, Chan MTV, Srinathan SK, et al. Association of postoperative high-sensitivity troponin levels with myocardial injury and 30-day mortality among patients undergoing noncardiac surgery. JAMA. 2017; 317:1642-51.

6. Neumann JT, Sörensen NA, Ojeda F, Renné T, Schnabel RB, Zeller T, et al. Early diagnosis of acute myocardial infarction using high-sensitivity troponin I. PLoS One. 2017;12:e174288.
7. Westermann D, Neumann JT, Sorensen NA, Blankenberg S. High-sensitivity assays for troponin in patients with cardiac disease. Nat Rev Cardiol. April 6 , 2017 [Epub ahead of print].

8. Santaló M, Martin A, Velilla J, Povar J, Temboury F, Balaguer J, et al. Using high-sensitivity troponin T: the importance of the proper gold standard. Am J Med. 2013;126:709-17.

9. Cubero-Gallego H, Lorenzo M, Heredia M, Gómez I, Tamayo E. Diagnosis of perioperative myocardial infarction after heart valve surgery with new cut-off point of high-sensitivity troponin $\mathrm{T}$ and new electrocardiogram or echocardiogram changes. J Thorac Cardiovasc Surg. 2017;154:895-903.

10. Thygesen K, Alpert JS, Jaffe AS, Simoons ML, Chaitman BR, White HD, et al Third universal definition of myocardial infarction. Circulation. 2012;126: 2020-35. 